disintegrated but unreacted portion of the country-rock embedded in the silicic acid gel (the latter being the product of the action of magmatic waters upon the rock). On the other hand, the demonstration of a regular crystalline silica constituent in opal would lend additional support to our conception, that is, the practically simultaneous first stage in the formation of opal.

1 Gildridge Road,

Manchester, 16.

${ }^{1}$ Van Bemmelen, $Z$. anorg. Chem., 13, 245 (1896). Bütschli, Verh. Nat. Med. Ver. Heidleburn, 6, 287 (1901).

ALCON C. COPISAROW

MAURICE COPISAROW "Colloid Chemistry: Principles and Applications", 184 (4th Ed.' 1937).

s Brewster, Rep. Brit. Assoc. (1844), Appendix, p. 9.

- Behrens, Ber. Akad. Wien., 64, 519 (1871)

${ }^{3}$ Copisarow, A. C., and Copisarow, M., J. Amer. Chem. Soc., 67, 1915 (1945).

- Levin and Ott, J. Amer. Chem. Soc., 54, 828 (1932); Z. Krist., 85 305 (1933). Dwyer and Mellor, J. Roy. Soc. New South Wales, 68, 378 (1933); 68, 47 (1934).

\title{
Nutritional Value of High-Extraction Wheat Meals
}

THE world-wide shortage of cereals has made it urgently desirable to attain a clear understanding of the nutritional value of bread prepared from high-extraction meals; hence it was thought that the following information, based on experience gained in South Africa, might be of value. In this country the old custom of making bread from meals of 90-100 per cent extraction, which are ground in small local mills, has lingered on in many of our rural areas. Moreover. since May 1941 all meal used for bread-making has been standardized at an extraction-level of at least 95 per cent-usually somewhat higher. Naturally nutritionists here have been disturbed by the evidence brought forward during the last few years, indicating that the high brought forward during the last few years, indicating that the high
phytic acid content of breads made from such meals has a deleterious phytic acid content of breads made from such meals has a deleterious poor utilization of constituents such as calcium, but may also adversely poor utilization of constituents such as calcium, but may also adversely affect the availability of this element present in the remainder of the
diet. This is all the more disturbing in a country where wheat and diet. This is all the more disturbing in a country where wheat and
maize constitute such a large proportion of the diet, and where other maize constitute such a large proportion of the diet, and where oth

The of calcium are apt to be consumed in very small quantities. investigations similar to those on which the above evidence is based investigations similar to those on which the above evidence is based. For this purpose we emploved healthy human subjects who consumed $1 \mathrm{lb}$. of our standard war bread daily. We have closely followed the methods and general procedure described by McCance and Widdowson magnesium, total phosphorus and phytic acid phosphorus for three magnesium, total phosphorus and phytic acid phosphorus for three adult males over somewhat lengthy periods. As suggested by these workers, iron balances were also carried out to check the accuracy of
the experimental and analytical technique employed. Full details will be published elsewhere, but our conclusions for calcium may be riefly summarized as follows :

(a) Subjects passing abruptly from their usual diet to one of lower calcium content and including a considerable amount of bread made from a high-extraction meal show an immediate negative calcium balance. Gradually, however, the body adjusts to the new conditions, so that, given time, it again begins to retain calcium and in due course the losses sustained are made good.

(b) The period of adjustment is shorter, and the loss of calcium reduced. if the disparity between the usual calcium intake and tha of the experimental diet is small. and if the calcium intake is maintained throughout at a level of about $10 \mathrm{mgm}$. per kilo body-weight. (c) Immediately on passing from the usual to the standard bread diet, it was observed that the phytic acid ingested was almost completely hydrolysed; on returning to the usual diet, with its lower phytic acid content, the proportion hydrolysed fell to that previously observed.

The foregoing may be illustrated in part by the flgures obtained for one of our subjects who was studied continuously for 22 weeks during the flrst two weeks, the usual diet was consumed, followed by nine weeks in which $1 \mathrm{lb}$. of war bread was eaten daily.

\section{Subject's weight}

$51 \mathrm{kgm}$.

CaLCIUM

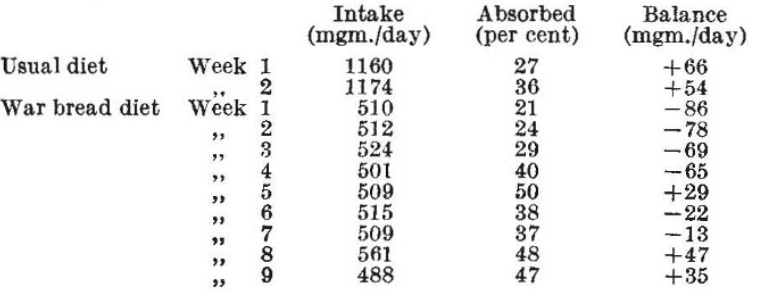

In this case, the sudden and drastic reduction in calcium intake was foljowed by a fairly prolonged period of adjustment. With another subject, whose usual calcium intake was considerably lower and did not differ appreciably from that provided by the experimental diet, it was found that adjustment to the phytic acid contributed by the bread has been established by the third week. It must be borne in mind, however, that our subjects had been consuming war bread for meveral years, and to some extent may have become habituated to an increased ingestion of phytic acid.
The ability of the body to accommodate itself to varying levels of intake has been emphasized by various workers (for example, Steggerda and Mitchell $^{2}$ ): it therefore appears essential in such work to continue observations for a considerable period before drawing conclusions, as has been advocated by Kraut and Wecker ${ }^{3}$. The point we wish to stress, however, is that the presence of fairly substantial amounts of phytic acid in the diet does not prevent such an adjustment taking place.

Indeed, this would appear to have been already established by the observations of other workers. Thus Nicholls and Nimalasuriya studied a child of seven years old for a period of nine days, who was living in Ceylon on the usual diet consisting mainly of cereals and pulses, both of which are known to be rich in phytic acid : the daily intake of calcium was only about $0.2 \mathrm{gm}$., yet he managed to absorb no less than 79 per cent of this meagre supply. Similarly, Basu et al. ${ }^{5}$ found that two out of three adult Indians studied, who were consuming equally small amounts of calcium obtained from rice and wheat, absorbed as much as 50 per cent and were even in positive balance. absorbed as much as 50 per cent and were even in positive balance. in these examples, accommodation to these diets had presumably been lifelong. Cruickshank et al. ${ }^{\circ}$ reported that the phytate-phosphorus of oatmeal was almost completely digested by four adult subjects when the calcium intake approached requirement. Here, as with our own subjects,

Only along such lines can we explain why the poorer Europeans of South Africa and particularly the Bantu population. who live almost exclusively on very high cereal diets, are able to absorb the small amounts of calcium present when accompanied by such large amounts of phytic acid. We are planning

While we do not wish to minimize the necessity of providing an
withents on dequate amount of calcium in the diet, we do suggest that if, for emergency reasons, such high extraction meals must be employed, the disturbance of calcium metabolism which undoubtedly does occur may be regarded as of a temporary nature.

\section{A. R. P. WALKER}

J. T. IRVING

National Nutrition Council,

P.O. Box 386 , Pretoria.

McCance, R. A., and Widdowson, E. M., J. Physiol., 101, 42 (1942). Steggerda, F. R., and Mitchell, H. H., J. Nutr., 21, 577 (1941). Kraut, H., and Wecker, H., Biochem. Z., 315, 329 (1943).

- Nicholls, L., and Nimalasuriya, J. Nutr., 18, 563 (1939). 27. 471 (1939).

Cruickshank, E. W. H. Duckworth, J., Kosterlitz, H. W., and Warnock, G. M.. J. Physiol., 104, 41 (1945).

\section{Splitting of Adenosine Triphosphate by Myosin}

ADENosine triphosphate is split by recrystallized myosin into adenosine diphosphate and free phosphate ; the adenosine triphosphat used and the diphosphate formed corresponded to Lohmann's formula. One of the 'phosphates' of the adenosine triphosphate is hydrolysed off easily (in 7 min. at $100^{\circ}$ in normal hydrochloric acid), while the other is stable (N/P, 1.13 : number of acid-equivalents, 3). If one 'phosphate' is split off, one additional acid-equivalent is formed. $\mathrm{NH}_{2}$ group can be liberated by desamidase or nitrogen dioxide. If the reaction is carried out in presence of a protein, adenosine monophosphate (adenylic acid) are formed in quantities depending on the duration of the experiment.

The adenosine diphosphate thus formed differs from that described above. One of its 'phosphates' is split off in $60 \mathrm{~min}$. (100 ${ }^{\circ}$. in normal hydrochloric acid), whereas the other takes three hours (N/P, 1.13).

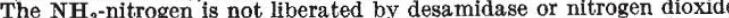
If one 'phosphate' is hydrolysed off, no new acid-equivalent is formed. The adenosine monophosphate also differs from 'muscle-adenylic acid'. Though N/P is $2 \cdot 26$, it has no free $\mathrm{NH}_{2}$, no nitrogen being liberated by desamidase or nitrogen dioxide. It seems probable that during the experiment an adenosine triphosphate is formed which contains no free $\mathrm{NH}_{2}$

A detailed report will appear after conclusion of the research in the Acta Hungarica Physiologica.

\section{Institute of Biochemistry,} April 30.

${ }^{1}$ Banga, I., Slud. Inst. Med. Chem., Univ. Szeged, 3, 64 (1943).

\section{A Possible Alternative Orientation in Protein Monolayers}

LITTLE is yet known regarding the change undergone by a native protein when it is adsorbed at an interface. The evidence at present available, which is largely based upon the preservation of the activity of enzymes in monolayers ${ }^{1}$, would seem to indicate that the molecules are subject to a change of form which remains reversible during the initial period of the adsorption.

I have recently been studying protein monolayers at the cyclohexanewater interface by a modiflcation of the Wilhelmy-Dervichian hanging. plate method ${ }^{2}$ in conjunction with the spreading procedure for a

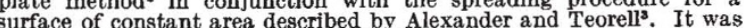
found impossible to obtain reproducible force-area curves for native here of propyl alcohol and sodium acetate solution recommended by 